\title{
Dielectric properties of fly ash
}

\author{
S C RAGHAVENDRA, R L RAIBAGKAR* and A B KULKARNI \\ Department of Applied Electronics, Gulbarga University, Gulbarga 585 106, India
}

MS received 17 July 2001; revised 21 November 2001

\begin{abstract}
This paper reports the dielectric properties of fly ash. The dielectric measurements were performed as a function of frequency and temperature. The sample of fly ash shows almost similar behaviour in the frequency and temperature range studied. The large value of dielectric constant in the typical frequency range is because of orientation polarization and tight binding force between the ions or atoms in the fly ash. The sample of fly ash is of great scientific and technological interest because of its high value of dielectric constant $\left(10^{4}\right)$.
\end{abstract}

Keywords. Fly ash; dielectric constant; ash utilization.

\section{Introduction}

Fly ash (FA) is a coal product generated from coal fired thermal power stations. It is gray in colour and alkaline in nature with $\mathrm{pH}$ ranging from 9 to 9.9 . About $70 \%$ of India's annual coal production is used in about 72 powergenerating plants and produce more than 90 million tons of coal ash per year. It is likely that it may cross over 100 million tons during 2001-2010 AD (Muraka et al 1987; Satyanarayan and Pushpalata 1991). Disposal of FA and bottom ash are today's burning problems as they have been considered as serious operational constraint and environmental health hazard (Sahu 1994). Hence there is tremendous interest in utilization and processing of FA/bottom ash/pond ash as starting raw material. It is used in the preparation of bricks and ceramic products (Sevelius 1997). For the first time, cordierite has been synthesized from FA (Sampathkumar et al 1995). Several methods have been reported for the preparation of zeolite from FA (Henmi 1987; LaRosa et al 1992; Shigemoto et al 1993). Fly ash was treated hydrothermally and the performance of this material as cracking catalyst was investigated with heavy oil fraction as the cracking feedstock (Ojha and Pradhan 2001). On the other hand, there were many experimental analyses on FA to determine its basic compositional, physical and chemical properties for technical studies and applications (Cumpston et al 1992; Sajwan et al 1995).

This work is in continuation of our earlier studies on d.c. conductivity behaviour of FA (Raghavendra et al 2000). Although a variety of physical and chemical properties of FA have been studied, the measurements on their dielectric properties are not exhaustive. In this

\footnotetext{
*Author for correspondence
}

paper, an effort has been made to determine the dielectric properties of FA.

\section{Experimental}

A fine fresh, clean and pure FA powder was collected from the Raichur Thermal Power Station, Raichur, Karnataka. The particle size of this FA ranged between 50 and $120 \mu \mathrm{m}$. It was abrasive and refractory in nature. Chemically, the FA was silica to an extent of $55-70 \%$, followed by alumina $10-18 \%$, iron oxide $6-20 \%$, and lime magnesia and alkalis varied between 1 and $5 \%$ each. It was reported that FA generally contains elements like $\mathrm{Cu}, \mathrm{Pb}, \mathrm{Cd}, \mathrm{Ag}, \mathrm{Mn}, \mathrm{Fe}, \mathrm{Ti}, \mathrm{Na}, \mathrm{Mo}, \mathrm{S}, \mathrm{P}, \mathrm{Zn}$ and $\mathrm{Cl}$ in different concentrations depending upon the type of coal used (Kaw et al 1990; Valkovic et al 1992; Karwas 1995).

The FA powder was compacted into pellet of $10 \mathrm{~mm}$ diameter. The pellets were heated at $950^{\circ} \mathrm{C}$ to obtain a hard solid sintered material. This pellet was used for the measurement of d.c. resistivity and capacitance using two-probe method. The dielectric constant $\left(\varepsilon^{\prime}\right)$ in the frequency range $10 \mathrm{~Hz}-100 \mathrm{kHz}$ was estimated in the temperature range $473-873 \mathrm{~K}$ by using the formula

$$
\varepsilon^{\prime}=C d / \varepsilon_{0} A,
$$

where $C$ is the capacitance of the pellet, $d$ the thickness of the pellet, $A$ the cross sectional area of the flat surface of the pellet and $\varepsilon_{0}$ the constant of permittivity of free space.

\section{Results and discussion}

The variation of dielectric constant $\left(\varepsilon^{\prime}\right)$ as a function of frequency at different temperature ranges $(T=473 \mathrm{~K}$, 
$573 \mathrm{~K}, 673 \mathrm{~K}, 773 \mathrm{~K}$ and $873 \mathrm{~K}$ ) is shown in figure 1. From the graph, it can be seen that the dielectric constant almost remains constant up to $100 \mathrm{~Hz}$. Later, there is a steady increase up to $1 \mathrm{kHz}$ and further decrease up to $1 \mathrm{MHz}$ in all the temperature ranges studied. This is attributed to the presence of space charge and orientation polarization owing to the number of elements present in FA. As the frequency increases, the value of $\varepsilon^{\prime}$ decreases suggesting that space-charge polarization is no longer contributing to it. The dielectric behaviour of our FA sample may be explained on the basis that the mechanism of polarization process is similar to that of the conduction process. The electronic exchange of number of ions in FA gives local displacement of electrons in the direction of an applied field, which in turn gives polarization. In normal dielectric behaviour, the dielectric constant decreases with increasing frequency reaching a constant value depending on the fact that beyond a fixed frequency of the electric field the electron exchange does not follow the alternating field.

However, as the temperature of the sample is increased, there is no dispersion in dielectric constant. This is because of the tight binding force between the number of ions or atoms (Goodman 1986). Moreover, the sample

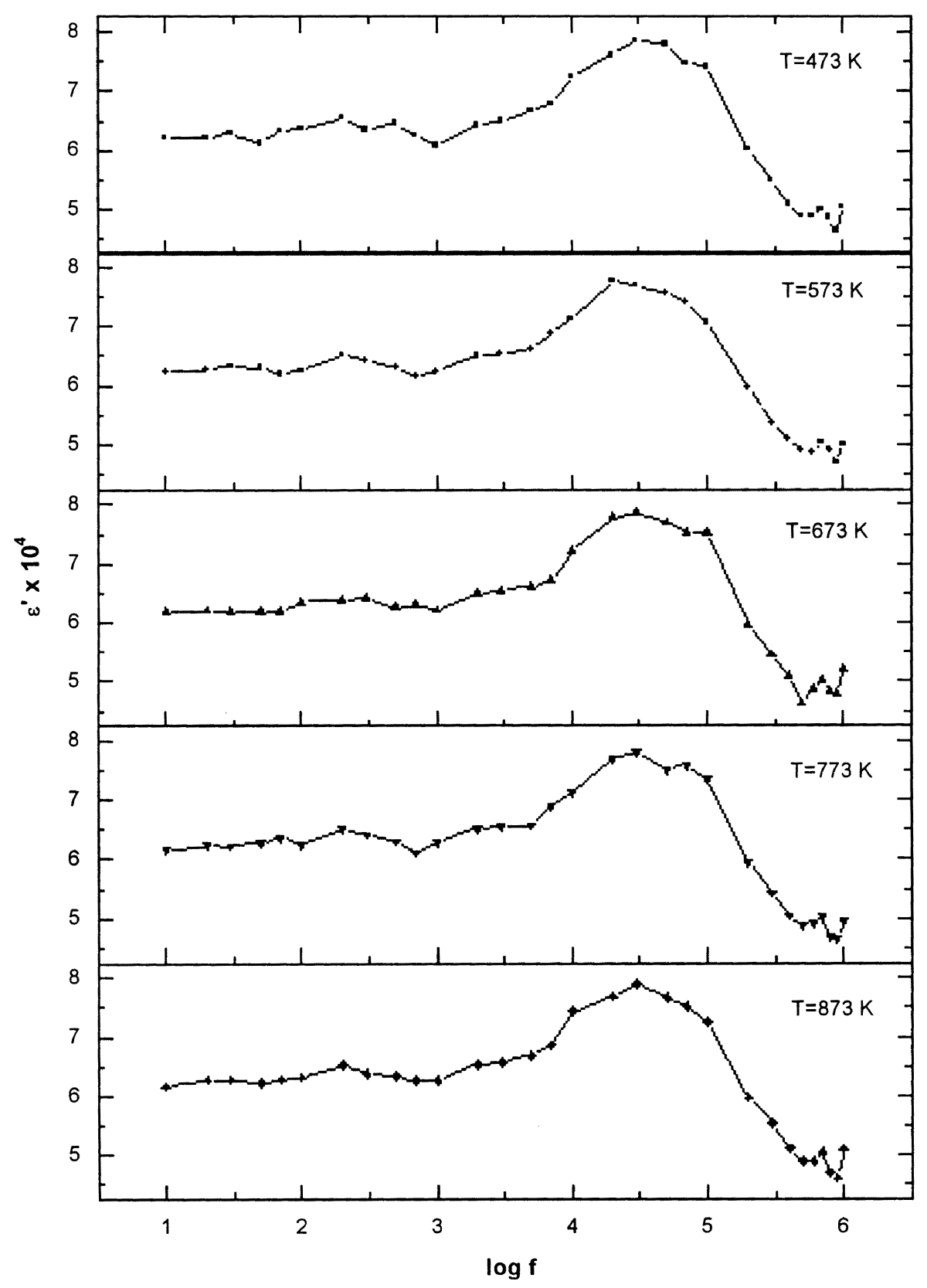

Figure 1. Dielectric constant $\left(\varepsilon^{\prime}\right)$ as a function of frequency at different temperatures. 
shows high value of dielectric constant of the order of $10^{4}$ and hence can be a best suitable material for capacitor fabrication and other electronic applications (Joshi 1997).

\section{Conclusion}

Dielectric property is an important property of material. Fly ash showed dielectric constant of the order of $10^{4}$, which can be a best suitable material for capacitor fabrication.

\section{Acknowledgement}

The authors would like to extend their sincere thanks to Dr L A Udachan, Professor and Head, Department of Physics, Sharanabasaveshwar College of Science, Gulbarga for providing the laboratory facilities.

\section{References}

Cumpston B, Shadman F and Risbud S 1992 J. Mater. Sci. 27 1781

Goodman G 1986 Ceramic materials for electronics (ed.) R C Buchaman (New York: Marcel Dekkar)

Henmi T 1987 Soil Sci. Plant Nutr. 33517
Joshi J P 1997 Asian J. Phys. 6115

Karwas C P 1995 J. Environ. Sci. Hlth. 301223

Kaw J L, Khanna A K and Waseem W 1990 Expt. Pathol. 3949

LaRosa J L, Kwan S and Grutzeek M W 1992 J. Am. Ceram. Soc. 751574

Muraka I P, Boyd R H and Harbert H P 1987 Solid waste disposal and reuse in the United States (ed.) I P Muraka (Boca Raton F L: CRC Press Inc.) p. 95

Ojha I K and Pradhan N C 2001 Indian J. Engg. Mater. Sci. 8 100

Raghavendra S C, Raibagkar R L and Kulkarni A B 2000 D.c. resistivity behaviour in fly ash, National seminar on physicochemical studies of solids including minerals and coal (Dhanbad: Indian School of Mines) CP/42

Sahu K C 1994 Power plant pollution: cost of coal combustion, Survey of the environment (Madras: The Hindu) pp 47-51

Sajwan K S, Haroldornes W and Youngbold T 1995 J. Environ. Sci. Hlth. 301327

Sampathkumar N N, Umarji A M and Chandrashekar B K 1995 Mater. Res. Bull. 301107

Satyanarayan G and Pushpalata K 1991 J. Adv. Plant Sci. 4289

Sevelius D 1997 Key Engg. Mater. 132-136 2272

Shigemoto K, Hayshi H and Miyaura K 1993 J. Mater. Sci. 28 4581

Valkovic O, Jaksic M, Caridi A, Cereda E, Haque A M I, Cherubini R, Maschini G and Menapace E 1992 Nucl. Instrum. Meth. Phys. Res. B69 479 